Proceedings

\title{
Therapeutic procedure with the use of kinesiology taping in women with painful menstruation
}

\author{
Hanna Mosiejczuk ${ }^{1}$, Żaneta Ciosek ${ }^{2}$, Magdalena Ptak ${ }^{3}$, Przemysław Wróblewskii ${ }^{4}$, Iwona Rotter ${ }^{5}$ \\ 1 Department of Medical Rehabilitation and Clinical Physiotherapy \\ Pomeranian Medical University ul. Żołnierska 54b, Szczecin 71-210 Poland ; hanna.mosiejczuk@pum.edu.pl \\ 2 Department of Medical Rehabilitation and Clinical Physiotherapy \\ Pomeranian Medical University ul. Żołnierska 54b, Szczecin 71-210 Poland; zaneta.ciosek@pum.edu.pl \\ ${ }^{3}$ Department of Medical Rehabilitation and Clinical Physiotherapy \\ Pomeranian Medical University ul. Żołnierska 54b, Szczecin 71-210 Poland; magdalena.ptak@pum.edu.pl \\ ${ }^{4}$ Kinesis Scientific Circle at the Department of Medical Rehabilitation and Clinical Physiotherapy \\ Pomeranian Medical University ul. Żołnierska 54b, Szczecin 71-210 Poland; \\ przemek.wroblewski95@gmail.com \\ ${ }^{5}$ Department of Medical Rehabilitation and Clinical Physiotherapy \\ Pomeranian Medical University ul. Żołnierska 54b, Szczecin 71-210 Poland; iwona.rotter@pum.edu.pl \\ * Correspondence: hanna.mosiejczuk@pum.edu.pl, +48-695-633-788
}

Publisher's Note: MDPI stays neutral with regard to jurisdictional claims in published maps and institutional affiliations.

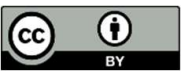

Copyright: (c) 2021 by the authors. Submitted for possible open access publication under the terms and conditions of the Creative Commons Attribution (CC BY) license (http://creativecommons.org/licenses/by/4.0/).

\begin{abstract}
Introduction: Painful menstruation is a problem affecting a large part of the population of women of childbearing age. It is estimated that up to $90 \%$ of them suffer from pain during menstruation, which prevents them from normal functioning and performance of their tasks and lead to increasing frustration and nervousness. Purpose: The aim of this study is to examine the effectivness of the application of kinesiology taping proposed by its author in relations to the alleviation or complete elimination of pain associated with dysmenorrhea. Materials and methods: The study involved 30 women who experience the problem of dysmenorrhea. They were divided into two groups of 15 people, one of whom received support using kinesiology taping, while the other did not receive such assistance. For the purposes of the research, an authorial anonymous questionnaire was created, which included a general questionnaire supported by the SF-36 quality of life questionnaire and 3 anonymous orginal questionnaires for each cycle that were recommended to be completed by the respondents after menstruation. Results: The proposed application of kinesiology taping has positively influenced for the reduction of complaints among women covered by it. Menstrual period was shorter for 9 women (3 without changes, 3 elongation). The application has led to the total elimination of the us of painkillers/anti-inflammatiries and other forms of support in 3 women, and in the case of 8 a small intervention or lack of it was necessary. Conclusions: The effectiveness and valence of the proposed application has been confirmed, and also the effects on other components of the menstrual cycle were noted.
\end{abstract}

Keywords: kinesiology taping; painful menstruation; dysmenorrhea; physiotherapy

\section{Introduction \\ Introduction:}

Painful menstruation (Latin dysmenorrhoea / dysmenorrhea) is a term that refers to disorders of the menstrual cycle during which a woman complains for severe pain. It is a quite embarrassing topic and often overlooked when talking to gynecologists, whether due to cultural conditions, or when a woman is ashamed of the problem and tries to heal it with standard home remedies. Depending on the availability of information sources and the honesty of the patients subjected to the research, it is estimated that in some countries of the world this problem may affect from a few to even $93 \%$ of women of reproductive age, usually under the age of 30, which constitutes a significant percentage of people and him in the light of exceedingly troublesome and burdensome in everyday 
life. Often these symptoms lead to the exclusion of women from everyday life and work, which also contributes to increasing stress and frustration for several days. It is worth paying attention to the fact that these symptoms may precede menstruation and starting several days before the actual bleeding $[1,2,3,4]$.

In recent years, flexible patches, used for wrapping literally the whole body and acting on many ailments, whether it is muscle pain, limitation of mobility, instability, or in the case of swelling or scars after treatments, during the treatment, are becoming more and more popular and equally accepted. pregnancy, as well as in female ailments. The above-mentioned examples are just a few of the possible applications of taping. The slicing action is carried out and used in several ways in many ailments. Its main functions include reducing pain, improving blood and lymph circulation in the vessels within the application, leading to the improvement of oxygenation and nutrition of tissues and the removal of inflammatory mediators from dysfunctional sites. [5,6].

Purpose: The aim of this study is to examine the effectivness of the application of kinesiology taping proposed by its author in relations to the alleviation or complete elimination of pain associated with dysmenorrhea. Additionally, the reduction or total elimination of the use of funds affecting the accompanying ailments was also taken into account, as well as the promotion of this method, improving the quality of life of the respondents. The infuluence of taping on the lenght of bleeding and its size was also considered remarkable and subject to analysis.

\section{Materials and methods:}

The study involved 30 women who experience the problem of dysmenorrhea. They were divided into two groups of 15 people, one of whom received support using kinesiology taping, while the other did not receive such assistance. For the purposes of the research, an authorial anonymous questionnaire was created, which included a general questionnaire supported by the SF-36 quality of life questionnaire and 3 anonymous orginal questionnaires for each cycle that were recommended to be completed by the respondents after menstruation. The subjects in the group who received support for taping received two applications with a 25\% I-shaped and Y-shaped stretch applied (Figure A1) to the abdominal and abdomen area for three consecutive cycles, which were applied depending on the possibilities of the subjects one or two days before the planned menstruation. The first I-shaped application was placed in the lower abdomen above the borderline of the pubic hair and led towards the edges of the outer iliac plates in such a way that it is only over the soft tissues and is applied in the supine position. The length of the tape has been individually selected for each woman. The voltage that was used in this application it was $25 \%$, while the base tension around the edge of the iliac plates was $0 \%$. The second Y-shaped application was placed in the xiphoid area of the sternum and led in the form of two equal stripes towards the borderline of the pubic hair in such a way that the navel was not covered by the tape and was put on in a standing position with the spine straightened during the extension. The length of the tape was also selected individually for each of the test persons. The tape tension used for this application was also $25 \%$ and the base voltage $0 \%$ around the sternum and the end of the lanes.

Statistical analysis was performed using the Statistica PL v. 13.0 PL package, (StatSoft, USA). Continuous and ordinal variables (e.g. pain scale) are presented by the arithmetic mean, standard deviation of the count, and the qualitative variables (respondents' choices) by the counts (n) and the appropriate percentages ( $\%$, fractions). Groups were compared with the non-parametric Mann-Whitney U test or analyzed with the Pearson Chi2 test. For all tests, statistical significance was adopted at the level of $\mathrm{p}$ $<0.05$.

The study was approved by the Bioethics Committee of the Pomeranian Medical University in Szczecin no. KB-0012/27/19 of 14.01.2019 
Results:

A statistically significant difference was noticed between the two groups in the case of the amount of bleeding, the values of which were presented by the use of tampons and / or pads $(\mathrm{p}=0.05)$ and calculated using the Mann-Whitney $U$ test. The intervals between cycles in the study group were shortened in 7 women, 6 of them noticed its extension, and one did not notice any changes. Due to the inaccuracy of the answer, no change could be determined in the case of one of the respondents. The most statistically significant changes were identified for cycles 1 and 3 ( $p=0.02$ and $p=0.03$, respectively) using the MannWhitney $\mathrm{U}$ test. Pain during bleeding appeared for 26 out of 45 cycles in total before the onset of menstruation, 17 times simultaneously with the onset of menstruation and twice in a different time period. A similar to statistically significant difference was noted for the third cycle $(p=0.09)$ using the Pearson Chi2 test. Among the 15 women assigned to the study group, as many as 14 of them reported a reduction in pain during menstruation after using kinesiology taping. Statistically significant differences were noted across all cycles $(\mathrm{p}=0.000134, \mathrm{p}=0.000197, \mathrm{p}=0.000042$, respectively), which were determined using the Mann-Whitney $U$ test. The occurrence of pain in places other than the lower abdomen is similar throughout all cycles. Statistically differences in the event of discomfort were noted in the 2 nd and 3rd cycle ( $p=0.008$ and $p=0.03$, respectively) using the Pearson's chi2 test. The ailments most often localized in the lumbar spine, and a similar statistical significance was observed in the case of the second cycle $(p=0.078)$, as determined by the Pearson Chi2 test. The time interval of pain symptoms has changed. In the case of 8 women, the length of the discomfort was shortened, in the case of 4 it was longer and in the 3 respondents no changes were noted. The subjective feeling about cycle abundance has changed over the course of ongoing research. In the case of 5 women, the abundance decreased ( 1 woman for 3 cycles, 2 for 2 cycles, and 1 for 1 cycle), 9 subjects did not notice any changes, while 1 signaled increased abundance for one cycle. The results collected using the questionnaire on the consumption of tampons and / or pads have changed. Out of 15 women subjected to taping, as many as 11 reported a reduction in the use of the above-mentioned, 3 observed their increased use, and one did not observe such a change. A similar to a statistically significant difference in relation to the group not receiving taping was observed in cycle $2(p=0.06)$ using the Mann-Whitney $U$ test. The duration of the bleeding also changed. In 9 subjects it was shortened, 3 out of 15 reported its extension and 3 no changes in their length. For 34 cycles, women signaled the occurrence of additional ailments that intensified the discomfort during menstruation. Statistical analysis showed that a significant change appeared only in the third cycle $(p=$ 0.01 ) and was determined using the Pearson Chi2 test, and its increase was noted over the course of 3 cycles. The most common symptoms were depressed mood, feeling weak and headache. The kinesiology taping application used for the purposes of this study was primarily intended to reduce pain. Over a total of 45 cycles, as many as in 21 women did not signal the need to use any means of alleviating symptoms, and in the case of 14 cycles, they required only minor intervention of the above-mentioned. Unfortunately, during 10 cycles, significant intervention was needed to reduce the discomfort. The statistical significance of these changes was observed in the 3rd cycle $(p=0.01)$ using the Pearson Chi2 test and it increased with the progress of the study. The questionnaire raised the issue of the presence of a restriction in carrying out everyday activities. Out of 15 women, 3 of them reported that the applied patching contributed to the elimination of the above mentioned ones in space 3 cycles and 3 women during 2 cycles. 9 women did not signal any changes. A change close to statistical significance was noted already in the first cycle $(p=0.099)$, while a significant difference in the third cycle $(p=0.005)$ was determined using the Pearson Chi2 test. Additionally, it was noticed that this difference increases with the duration of the research. Over the course of 45 cycles in total, as many as 33 women stated that the applied application was effective in alleviating the symptoms present during menstruation, while they expressed negative opinions about it 6 times. The 
respondents were also uncertain about the effectiveness of this form of coping with discomfort 6 times.

\section{Discussion:}

The conducted research provides positive data on the impact of the kinesiology taping application used for the purposes of this study. In line with the hypothesis, there was an improvement in the parameters taken into account in this work. Beneficial changes were noted in parameters such as pain strength, pain duration, subjective feelings about the amount of bleeding, reduction in the use of tampons and / or pads and bleeding time, the use of measures to alleviate or eliminate accompanying symptoms, and to minimize the existing limitations in daily activities. Statistical analysis showed no statistically significant differences between people assigned to the control group and the study group in terms of pain intensity in the general part and the duration of pain experienced, subjective feeling about the amount of bleeding, duration of bleeding during the analysis of consecutive cycles. A similar to statistically significant difference was noted when comparing the data collected over the three cycles in relation to the onset of symptoms in the 3rd cycle, and the location of pain in the 2nd cycle, consumption of tampons and / or pads in the 2nd cycle, as well as the presence of limitations in performing everyday activities in the 1st cycle. Statistically significant differences between both groups were noted in the amount of bleeding in the general part, as well as the interval between cycles for the 1st and 3rd menstruation, the intensity of pain, the occurrence of complaints other than the lower abdomen in the 2nd and 3rd cycle, the occurrence of additional symptoms in the 3rd cycle. statistically increasing significance over time, which means that these changes differ more clearly with the number of applications and subsequent cycles, as well as a reduction in the use of painkillers / anti-inflammatory agents and other forms of alleviation or elimination of symptoms in the 3rd cycle, which also increases with time and the difference in the occurrence of limitations in the performance of everyday activities in the 3rd cycle, also increasing in the time period. Due to the small number of publications and documentation on the application of slicing, it is worth paying attention to the available documents. Among them, there are proposals which, despite the fact that they are precisely described in the action and their application, do not present data relating to the feelings of people subjected to them, which does not prove about inaccuracies in the presentation, but about the proposed way to achieve the effect $[5,7,8]$. However, studies were carried out to determine the possible benefits of the application, which were to contribute to the reduction of pain and the taken pharmacological agents. The results of these studies are promising and confirm the assumptions presented by the authors, but they believe that they require continuation and broadening of their spectrum [9]. Among the available literature, there are examples of the use of kinesitherapy in relieving pain during menstruation. Such methods include exercises in the muscles around the spine, abdomen, pelvic girdle or directly acting on the structures of the pelvic floor and in the perineum, which are mainly aimed at relaxation of the mentioned structures. Particular attention is also paid to breathing through the diaphragmatic path, and the exercises are enriched elements of vibration and shaking. Unfortunately, there are no data on the impact of the above exercises on the discomfort experienced by women [10, 11].

\section{Conclusions:}

The kinesiology taping application proposed for this study reduced pain in 14 out of 15 subjects in the group subjected to it. The use of taping as an alternative source of alleviating or eliminating pain has been confirmed in the reduced or complete elimination of the means used so far by women. The use of taping during menstruation contributed to the improvement of the quality of life and reduction of limitations in the performance of everyday activities. The women covered by the research definitely consider the use of taping to be effective and sufficient in coping with the symptoms accompanying 
menstruation, which may result in their further promotion of this method among people suffering from painful menstruation.

\section{Figures}

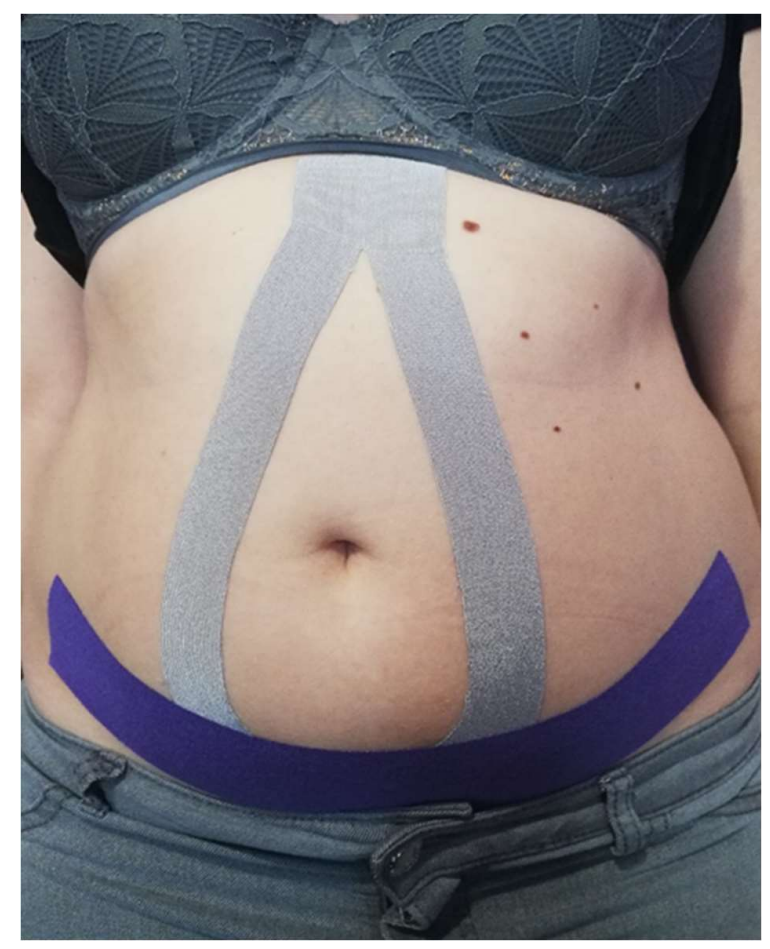

Figure 1. Figure 1 shows a complete application, which one of the respondents agreed to publish. Source: own material.

Funding: This research received no external funding

Conflicts of Interest: The authors declare no conflict of interest

\section{References}

1. Cho L.W.: Health-related quality of life among Chinese adolescent girls with dysmenorrhoea. Reproductive Health $2018 ; 15: 80$.

2. Min-Hui C., Hsiu-Fen H., Yi-Hsin Y., Huei-Mein C., Su-Chen H., Hsiu-Hung W.: Influencing factors of dysmenorrhoea among hospital nurses: a questionnaire survey in Taiwan. BMJ [onlne]. 2017;7:e017615. [przeglądany: 25 stycznia 2019]. Dostępny w: doi:10.1136/bmjopen-2017-017615.

3. Subasinghe A.K., Happo L., Jayasinghe Y.L., Garland S.M., Gorelik A., Wark J.D.: Prevalence and severity of dysmenorrhoea, and managment options reported by young Australian women. AFK November 2016; Volume 45, Number 11.

4. Sharma S., Deuja S., Saha C.G.: Menstrual pattern among adolescent girls of Pokhara Valley: a cross sectional study. BMC Women's Health 2016; 16:74.

5. Ilbeygui R.: Taping. Techniki - działanie - zastosowanie kliniczne. Wyd. 2. Wrocław: Edra Urban \& Partner; 2018. s. 3-9, 37-40, 264-266.

6. Mosiejczuk H., Lubińska A., Ptak M., Szylińska A., Kemicer-Chmielewska E., Laszczyńska M., Rotter I.: Kinesiotaping jako interdyscyplinarna metoda terapeutyczna. Pomeranian J Life Sci 2016; 62(1):60-66.

7. Weiss D.: Taping: taśmy na bóle mięśni i inne dolegliwości. Kielce: Wydaw. JENOŚĆ; 2015. s. 12-16, 26-41, 106-107. ISBN 97883-7971-084-3.

8. $\quad$ Langendoen J., Sertel K.: Przewodnik tapingu dla każdego: skuteczne łagodzenie bólu i szybka pomoć na 160 dolegliwości. Białystok: Wydaw. Vital; 2016. s. 21-28, 48-51, 152-155. ISBN 978-83-65404-35-0.

9. Tomás-Rodriguez M.I., Palazón-Bru A., Martinez-St. John D.R.J., Toledo-Marhuenda J.V., Asensio-Garcia M. del R., Gil-Guillén V.F.: Effectivness of medical taping concept in primary dysmenorrhoea: a two-armed randomized trial. Sci Rep 2015; $13 ; 5: 16671$.

10. Kozłowska J., Curyło M.: Rehabilitacja w ginekologii i położnictwie -

część praktyczna. Kraków: Akademia Wychowania Fizycznego im. Bronisława Czecha; 2013. s. 72-75. ISBN 987-83-628-9127-6. 
11. Reinholz-Jaskólska M.: Miejsce fizjoterapii we współczesnej ginekologii. W: Szukiewicz D.: Fizjoterapia w ginekologii i położnictwie. Warszawa: Wydaw. Lekarskie PZWL; 2012. s. 119-121. ISBN 978-83-200-4320-4. 